\title{
Audio-Visual Aids to Teaching
}

\author{
Reviews of Recent Videotapes
}

\author{
Psychological Defence Mechanisms (UK, 1984, 22 mins)
}

This videotape (not film as referred to in the voice-over) is designed for medical students during their clinical training. Defence mechanisms are illustrated by brief vignettes of varying length. The two longest stories are those devoted to what one might consider a normal bereavement reaction by denial and a more pathological use of projection. Other snippets refer to denial, projection, regression and repression. Most of the examples are clear with the exception of students chewing pens and spectacles cited as examples of thumb-sucking denoting regression in times of stress.

The demonstrations refer to 'normal' defence mechanisms and 'pathological' examples. It is not made clear that similar mechanisms may exist as a constructive method of handling anxiety or in a more distorted form where there may be evidence of psychiatric disorder. The gradation between these two situations is also not discussed.

The quality of the camera work and colour use is good but the sound has been inadequately controlled. If the volume is set to hear the voices of the actors, the voice-over booms loudly above them while if the voice-over is acceptable one cannot clearly hear the conservation between the actors.

The patients on this tape have given their consent to its being viewed by students and professionals in the medical and mental health fields. This consent lasts only until 1989 and the makers reserve the right to retrieve the tape for re-editing after that date.

The price is $£ 50$ for $U$-matic and $£ 40$ for VHS, plus $£ 3$ packing and postage. The tape is available from Dr Andrew Powell, Department of Psychotherapy, Clare House, St George's Hospital, Blackshaw Road, London SW17 0QT.

C. P. SEAGER

University of Sheffield

\section{Chasing the Bandwagon (UK, 1985, 23 mins)}

Mustard powder. Get hooked, and before you know where you are, you're sniffing it, licking it, and even putting your feet in bowls of it. But beware the pusher who adulterates the real stuff, with..... yes, custard powder!

So says Lenny Henry, the funny front man for this engaging educational film on drug abuse, aimed specifically at those most at risk-young teenagers. And of course the mustard is heroin, providing the opportunity for laughs, but not at the expense of taking the subject seriously. Indeed, the film clearly aims to get young people thinking about the dangers of experimenting with drugs. It does this not by telling them what to do, which might drive away those who might benefit most, but by presenting drug issues in a way the audience can easily identify with. For example, the problem of saying no to friends or pushers. In the end, the audience is left to decide for themselves, as of course they have to in real life. All this is achieved by watching the funny and sometimes tragic antics of the mustard 'snackers' and then seeing Lenny Henry discuss issues raised in the sketch with a group of 13-14 year olds.

The film itself is short on information, but in fairness is meant solely as trigger material to initiate interest and discussion. An accompanying information pack includes booklets, posters, a directory of helping agencies and teaching notes. Although the film could have emphasised specific audience discussion points more, since it tends to ramble towards the end, generally both film and information pack are well thought out and likely to be attractive to a teenage audience. It should prove valuable for use by professionals working with young people, particularly teachers, doctors, social workers and nurses.

Commissioned by: National Council of YMCAs. Production: Boulton Hawker Films. Format: $16 \mathrm{~mm}$ film VHS/Beta/U-matic/V2000 video tapes. Distributors: CFL Vision, Chalfont Grove, Gerrards Cross, Bucks SL9 8TN. Purchase price: VHS/Beta $\mathbf{8 0}$. U-matic/V2000 295 . Hire f16.

\section{Nicholas Rose Department of Psychiatry, Oxford}

\section{Agoraphobia-Psychological Assessment Interviewing} (UK, 1985, 180 mins)

This programme comprises four interviews carried out by a clinical psychologist of a patient with agoraphobia. There is a useful descriptive leaflet which states that an unusual feature of the tapes is that they represent real time. This perhaps might be a problem: the first interview lasts some $\mathbf{4 0}$ minutes and plays without comment or break. At the end of the interview there is a summary by a clinician of what he thought happened during the interview. He says some useful things about interview skills in a general sense but it is difficult to link them to the relevent point of the interview.

The clinical details were taken from a real case and the material has an authentic 'feel' to it. The history unfolds in a natural way and nicely illustrates the typical complexity of such a case-for example it transpires that her husband has recently had an affair. The tapes also make the point that it may well take several interviews to get anything like 